\title{
When Green Was The New Black: What Went Wrong With China's Eco-City Movement?
}

\author{
ZHONGJIE LIN \\ University North Carolina at Charlotte
}

Coined by Richard Register in Ecocity Berkeley (1987), the concept of "eco-city" originated from the fundamental objective of sustainability in urban planning, design, and management to create ecologically healthy cities that enable residents to live a high-quality life with minimal impact on the environment. The 1992 United Nations Earth Summit in Rio de Janeiro and the resultant sustainable development programme, Agenda 21, formed the institutional backbone to support such an idea. However, until the end of the twentieth century, the eco-city remained mostly in theoretical discussions with only a few modest practical examples in Europe, such as Schwabach in Germany or the BedZED housing development in England. It was not until the last decade that an increasing number of large-scale projects translating the concept into practice made it a global phenomenon. This occurrence coincided with the continuing growth of urban populations, which crossed the $\mathbf{5 0 \%}$ threshold in $\mathbf{2 0 0 7}$. Asia seems to have emerged at the forefront of eco-city development as the region in general is experiencing rapid urbanization. A number of high-profiled projects have been carried out in different countries including Kitakyushu of Japan, Songdo in South Korea, DelhiMumbai Industrial Corridor in India, and Masdar City in the United Arab Emirates.

Possibly the most ambitious eco-city movement, at least in terms of the number of initiatives and their scale, is currently taking place in China. A 2009 World Bank report revealed that more than 100 eco-city initiatives were under development; and according to a survey conducted by Chinese Urban Science Research Council in 2011, a total of 259 municipal governments have announced their intent to become an "eco-city" or "low-carbon city," which accounted for $90.2 \%$ of all prefectural level cities in China. It took only a few years for the eco-city to become a nationwide movement that some researchers called the "green leap forward." If these numbers reflect the reality of current practice of city building to a reasonable extent, China should have become one of the greenest societies in the world. However, at the macro-scale, China's volume of carbon emission has continued to climb; and at the micro-level, if one visits some of the numerous new towns or gigantic redevelopment projects across the country, it is difficult to detect any major impact of this concept on development patterns. In many cases, the term eco-city, or "green city" as is more commonly talked about, remains part of the propaganda of local governments to promote their municipality, compete for investment, expand urban territory into the countryside, and push forward large-scale developments. In many of the high-flown master plan and official announcements, these descriptors are used in a similar manner as previous trendy terms like "international city" or "high-tech city," often without many concrete measures specified toward the goals.

Nonetheless, some Chinese cities have taken the title of eco-city more seriously. Many of them are high-profile projects with strong upper-level governmental support. Several have established some forms of international collaboration to introduce proven experience of eco-city development from Western countries and have involved global teams of planners, architects, and engineers in designing the project. These developments were laid-out with comprehensive master plans, and some of them prepared detailed Key Performance Indicators to assess environmental outcomes. They were widely publicized and promoted as examples of sustainable urbanization. However, most of these projects also stumbled along: Dongtan Eco-city in Shanghai, intended as the world's first carbon-neutral city when created in 2004, was officially cancelled; Caofeidian Eco-city in Tangshan, after reckless reclamation of over $210 \mathrm{~km} 2$ of land, is essentially a bankrupt project; Chenggong New Town in Kunming, a planned city for one million inhabitants, became known as one of China's largest ghost towns; even Binhai Eco-city in Tianjin, a well-funded and relatively successful initiative backed by the state, has seen its development and population growth continue to lag behind projected targets, and was criticized for acting against certain principles of sustainability. What went wrong with Chinese eco-cities?

To be sure, there is no lack of policy guidance and administrative support for the sustainable city from the central government. As the nation is facing greater environmental pressure from unprecedented urbanization and continued industrialization, the administration has recognized the urgency of coping with these challenges and incorporated agendas to develop sustainable cities in the nation's 11th Five-Year Plan starting in 2006, which included a Renewable Energy Medium-and Long-Term Plan. In 2007, The 17th National Congress of the Communist Party of China put forward the low-carbon eco-city model as an important part of the overarching agenda of "eco-culture" for the building of "a harmonious world characterized by sustained peace and common prosperity." More recently, "urbanization" 


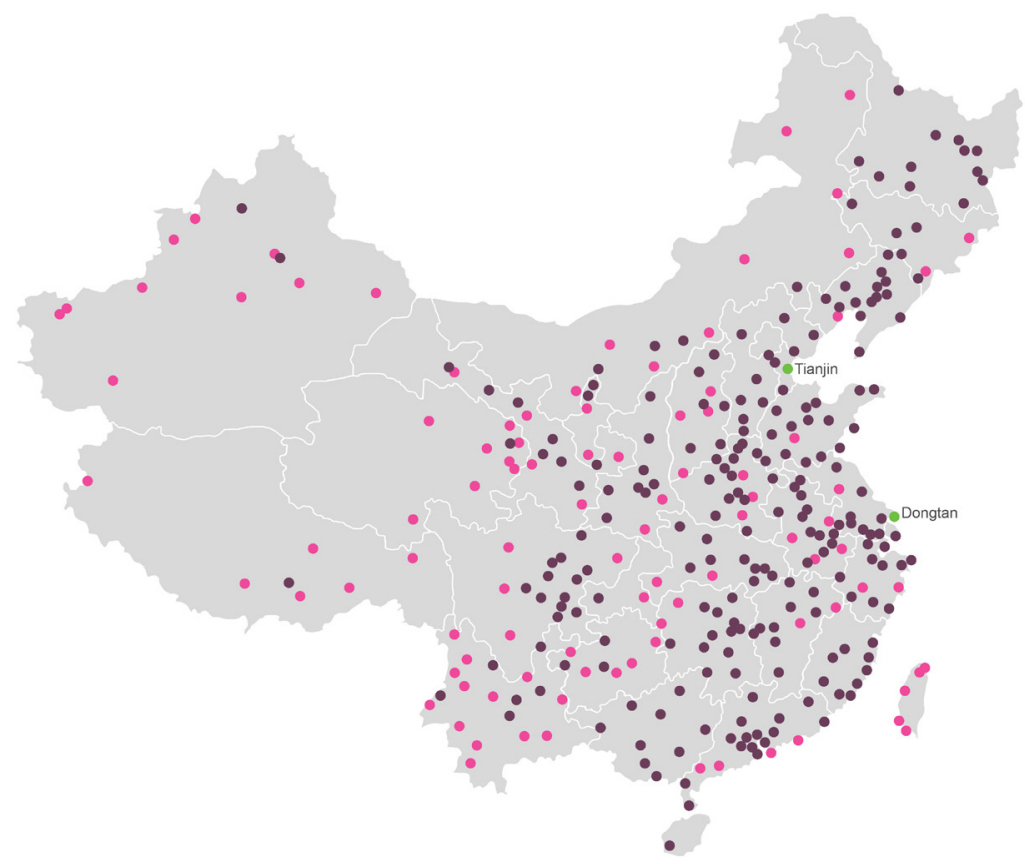

Fig. 1: Locations of Eco-city and Low-carbon city projects in China. Source: Li, Xun, 2011

"Introduction to Low-carbon Cities in China," presented at the Institute for Building Efficiency Roundtable Discussion, August 4, 2011.

was highlighted in the 18th CPC National Congress in 2012, and advocated by Premier Keqiang Li as the key to Chinese economic restructuring in the following decade. $\mathrm{Li}$ called for leading the country's mass urbanization toward a sustainable path to create new venues for jobs, increase consumptions and investments, balance mega-cities with small towns, and improve energy efficiency and air quality. These directives led to guidelines and initiatives to encourage local governments to pursue eco-city developments. For instance, the Ministry of Environmental Protection (MEP) and the Ministry of Housing and Urban-Rural Development (MoHURD) have established their respective standards for eco-cities and low-carbon cities to guide the development of local initiatives. The central government also facilitated a number of state-level demo eco-city projects, including Dongtan Eco-city in 2004 and Tianjin Eco-city in 2007, and attempted to use them as duplicable models in promoting sustainable urban development in the country.

Just like many other policies, however, the idea shifts as it moves from a directive of the central administration to implementation at the local level. The provincial and municipal governments, as well as developers commissioned to carry out the eco-city projects, have different agendas that stem from their respective political and economic interests. The top-down approach that most eco-city initiatives rely on might be effective to start a large-scale project, but often leads to the mismatch of resources that encourage land speculation, and compromises the objectives of reducing carbon emission and building livable communities. Residents are seldom involved in the initiatives, excluded from most financial benefits and incentives. As a result, these ambitious eco-city projects often fall into two differing categories or a combination thereof: a futurist grand project with a comprehensive vision and cutting-edge technologies, yet difficult to execute; or a profit-aimed conventional development dressed in "green" clothes and decorated with "green" ornaments. A revisit of two significant model eco-city projects, Dongtan and Tianjin, can provide insights into several issues affecting the ongoing Eco-city Movement with both commendable efforts and major obstacles.

\section{DONGTAN AND TIANJIN: FROM THE UTOPIAN TO THE UTILITARIAN}

Even before Masdar was initiated, China had planned the world's first carbon-neutral eco-city called Dongtan, to be built on Chongming Island in Shanghai. Dongtan was intended as a wholesale experiment of ecological development on a comprehensive urban scale. It was endorsed by both Chinese and British central governments. Arup Group Limited was hired to draw up its master plan and provide design and technical consultation; and Shanghai Industrial Investment Co. Ltd. (SIIC), a state-owned development firm, was commissioned for its execution. Occupying 630 hectares of the alluvial island at the estuary of Yangtze River, the new city was expected to house 400,000 residents by 2050 .

Aiming for a global example of sustainability, Arup's newly formed international planning practice team laid out an ambitious plan for Dongtan, integrating the latest environmental technologies. The goal was to use a 60 percent-less carbon footprint than a normal city in China, and to achieve a 66 percent reduction in energy demand. When built, Dongtan would use 100 percent renewable energy, 40 percent of which would be supplied by bioenergy. The city would recycle and reuse all wastewater. Landfill waste would be reduced by 83 percent. No fossil-fuel transportation would be allowed--only hydrogen and electric vehicles 
Fig. 2: Rendering of Dongtan Eco-city. Courtesy of Arup.

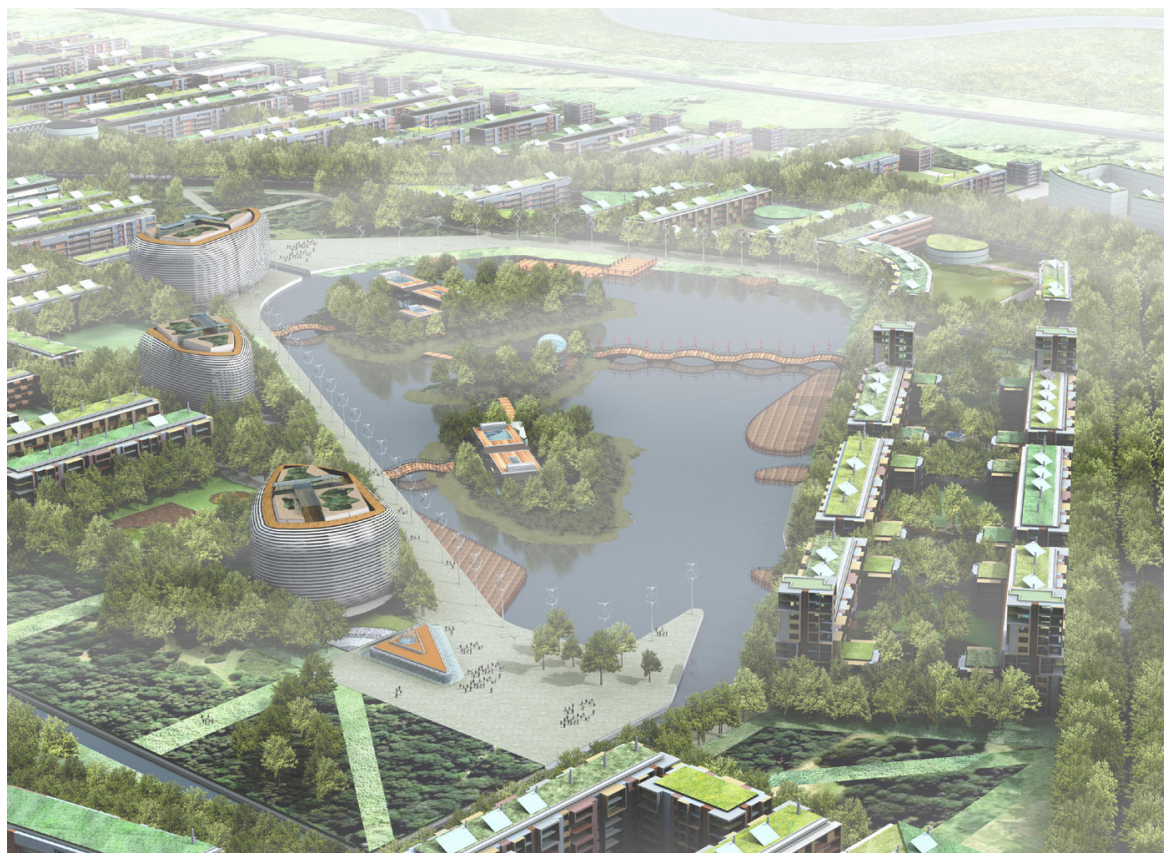

would be permitted within the city. Visitors coming with conventional petrol-fueled cars would have to leave their cars outside Dongtan and take public transit. The first phase of the new city would be organized into three villages around the city center. All housing would be located within the radius of seven minutes' walking to public transportation. Moving away from the prevalent high-rise typology in Chinese cities, the plan proposed midrise dwellings of five to eight stories, resulting in a density of 75 units per hectare. It would also preserve expansive green and water features across the city. To support employment within the city, an institute of environmental study was proposed as the central program for the first phase, along with commercial, entertainment, and cultural facilities.

Arup's work on the project was completed in 2006 and handed over to SIIC to be reviewed by the government. The original timetable called for the first phase be completed by 2010, the year Shanghai hosted the World Expositions, enabling the city to showcase its commitment to building a green future. However, no construction ever took place and the project was cancelled in 2009. Among other factors like political scandal of municipal officials and environmentalists' campaigns, there was an obvious disconnection between a utopian vision and the necessary design and financial measures to realize it. The plan suggested the new town not only be designed and built in the most ecological way possible, but also to be governed and managed in a completely different manner from any other city in the country, from garbage collection to power generation and supply. The last decade saw proliferation of the automobile in China, and by 2010, the country has become the largest producer and market of passenger cars by any nation in history, with numbers continued to soar. Banning fossil-fuel cars in the city, along with other measures like thorough recycling, represented a drastic departure from current Chinese society and its living style and demanded the city be segregated from its surrounding, a characteristic later manifest in Masdar. The enormous upfront cost and an unsecured marketability due to the extra cost falling on the consumer side must have affected the progress of the project. The worldwide recession in 2008 also raised the concern whether the project could afford the high cost of building and operation when international funding became unavailable.

In 2008 , the central government took the lead to create another new flagship eco-city, Tianjin Eco-city, under a partnership with Singapore, in which two countries split the share of the joint venture. About forty kilometers from Tianjin downtown, the Eco-city occupies nearly 35 square kilometers and will be home to 350,000 residents when completely built in 2020. It aspires to be a "thriving city that is socially harmonious, environmentally friendly and resource-efficient - a model for sustainable development." The choice of the site with its majority being saline-alkali land and wasteland indicates the governments' awareness of ecological challenges, the realization of limited land resources and the determination to tackle these issues. In 2014, a three-km2 pilot area was completed with approximately 10,000 residents living there. In addition, approximately 1,000 businesses attracted by financial incentives have registered in the Eco-city.

The parties creating Tianjin Eco-city learned from the lesson of Dongtan, and followed a different approach - a much more pragmatic one - to develop this project despite an equally ambitious plan. The primary strategy of controlling the environmental outcomes was a comprehensive guideline including 26 Key Performance Indicators (KPIs) based on "the current Chinese national standards and best practices in Singapore." 


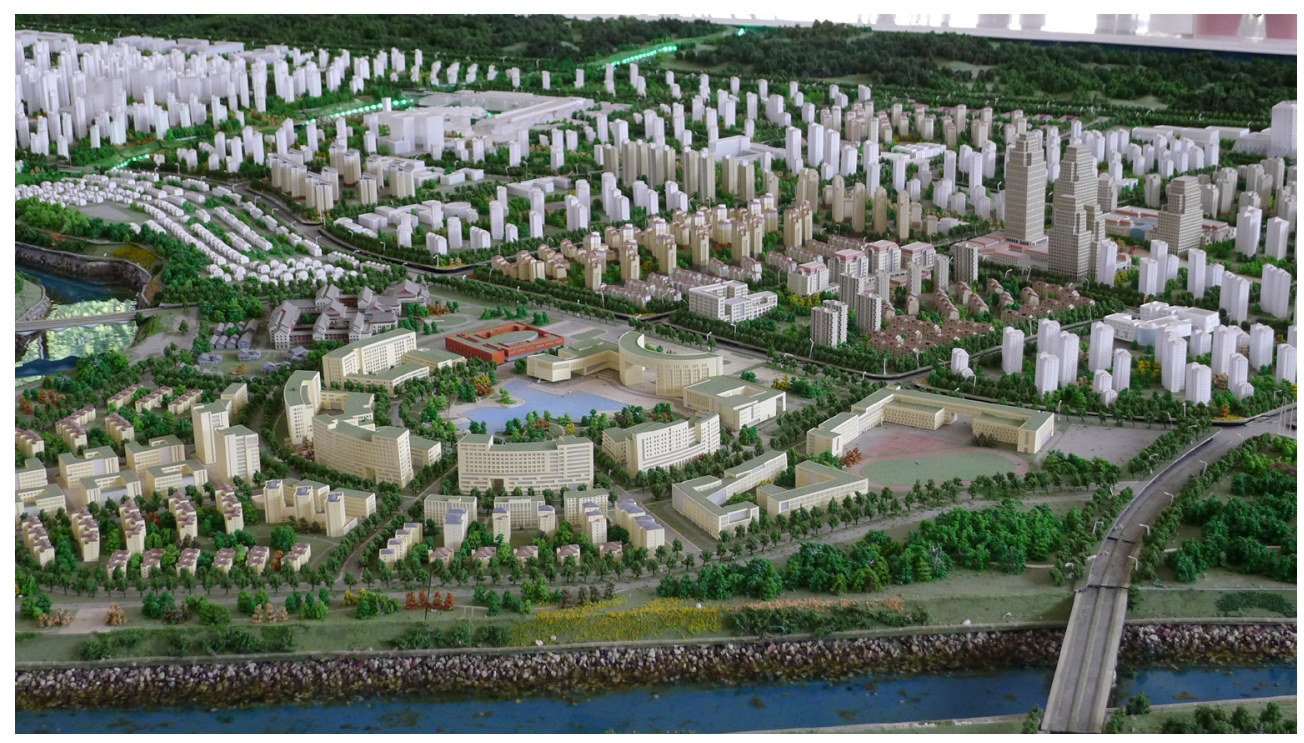

Fig. 3: Model of Tianjin Eco-city.

Photography by author.

Among these KPIs are several codes that represent notable improvements from the prevailing practice, such as preserving wetland, making tap water potable, and demanding all constructions meet China's Green Building standards. It is also commendable that the eco-city set a firm cap on carbon density - 150 tons carbon emission per million dollars of Gross Domestic Product. However, a few other KPIs are not so impressive. For instance, renewable energy would account for 20 percent of the total energy consumption by 2020, only a small step forward from China's national plan that requires 15 percent of renewable energy nationwide by 2020. Another KPI calls for 20 percent of residential development to be subsidized affordable housing, but the number of affordable housing units in Tianjin has accounted for 50 percent of the total residential development since 2011.

The pragmatic approach to city building is also reflected on its physical environment. In fact, Tianjin Eco-city appears to be fairly conventional and not much different from the urban landscape one would see in other Chinese new towns, although the solar panels and wind turbines scattering in the city seem to remind people of its identity as an ecocity. The residential neighborhoods and business centers were designed as super-blocks, each one occupying about 40 acres with clusters of freestanding high-rises indifferent to the site and context. In these gated communities, the residential towers sit upon a one-story podium of parking deck that occupies the entire block. As a result, the shared outdoor spaces of the community, which in this case are located on top of the deck, are segregated from the streets and sidewalks around. The blocks are surrounded by six-lane avenues designed for fast traffic without much consideration of cyclers and pedestrians. With the enormous urban scale apparently in favor of the automobile and only one light-rail line planned for the entire city with an indeterminate timetable for construction, it is suspicious how the goal of $90 \%$ green transportation in the KPIs could be met.
The mixed agendas presented in the KPIs and the conventional urban form as it is planned and partially built are results of a utilitarian notion of eco-city, which in turn stems from the top-down path characterizing urban policy and developmental mechanism in China. Tianjin Eco-city is typical of such top-down new town projects, led by the government and developed primarily by state-owned companies along with their Singaporean counterparts. As a new town built from scratch, Tianjin focuses on attracting population and investment through promoting the eco-city as a place with a higher-standard living environment and better opportunities for businesses. The governmental agents and developers shrewdly chose the indicators that could help enhance the eco-city's competitive advantage without committing to some high-expense sustainable items. The real estate sector in particular has a lot of influence in the direction of eco-city development. Developers view the concept of eco-city as a selling point, and associate it with such values as "luxury". The financial returns from land development are the primary economic driver of such projects. Although the nation has dedicated funds to support ecological developments, most of the subsidies go directly to the developers, while residents have little share of the financial benefit. As a top-down new town development, the residents have very limited, if any, influence on its plans, standards, implementation process, and other decisions.

The mixed agendas presented in the KPIs and the conventional urban form as it is planned and partially built are results of a utilitarian notion of eco-city, which in turn stems from the top-down path characterizing urban policy and developmental mechanism in China. Tianjin Eco-city is typical of such top-down new town projects, led by the government and developed primarily by state-owned companies along with their Singaporean counterparts. As a new town built from scratch, Tianjin focuses on attracting population and investment through promoting the eco-city as a place with 
Fig. 4: Street views of Tianjin Eco-city. Photography by author

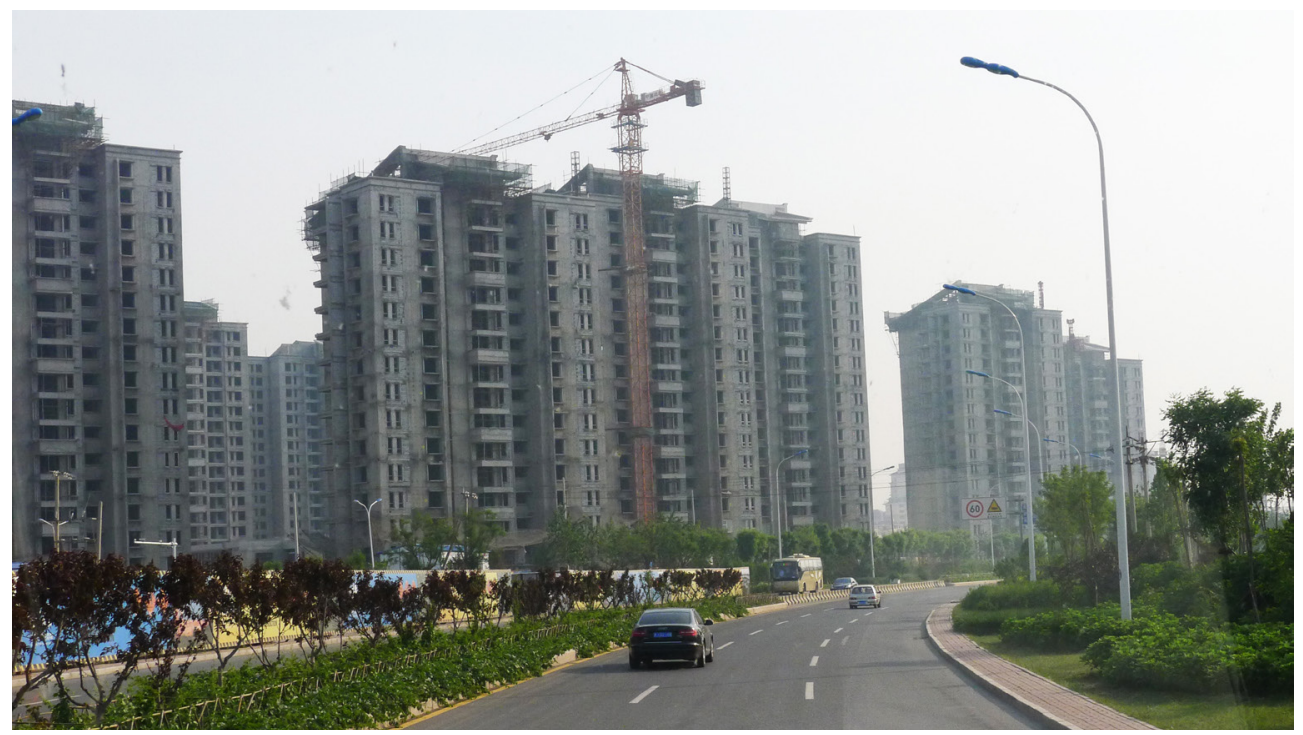

a higher-standard living environment and better opportunities for businesses. The governmental agents and developers shrewdly chose the indicators that could help enhance the eco-city's competitive advantage without committing to some high-expense sustainable items. The real estate sector in particular has a lot of influence in the direction of eco-city development. Developers view the concept of eco-city as a selling point, and associate it with such values as "luxury". The financial returns from land development are the primary economic driver of such projects. Although the nation has dedicated funds to support ecological developments, most of the subsidies go directly to the developers, while residents have little share of the financial benefit. As a top-down new town development, the residents have very limited, if any, influence on its plans, standards, implementation process, and other decisions.

From Dongtan to Tianjin, the attempts of building eco-cities in China moved from a utopian project to a utilitarian practice. During this process, the core ideas of eco-city gradually conceded to prevailing methods of land development and became subordinate to the agendas centered at local economic development; although, a number of ready-made products or technical standards, such as those related to green building, made their way to the design and construction market. The utilitarian approach now dominates the practice. Eco-city projects in China have largely followed the model of Tianjin Eco-city, carrying out planning and development in a top-down manner with preset technical indicators confined within existing parameters of urbanization. As the primary objective of such projects lies in the pursuit of added real estate value in the concept, there hasn't been much of a major breakthrough in term of the eco-city. The "green" remains largely as an apparel, and not in the soul, of these developments
THREE PITFALLS OF DEVELOPING ECO-CITY IN CHINA

Ten years have passed since Dongtan Eco-City was initiated, but an authentic and successful eco-city is yet to appear in China despite numerous attempts. In the meantime, the term is used uncritically in all sorts of projects, and turned into sales gimmick for real estate. A question must be asked under such circumstance: is eco-city still a useful concept to promote good practices of urban design and development? In my opinion, the answer is positive. Sustainability and Livability, two primary values of an ecologically healthy city as Register advocated in his original writing, remain key issues of city building in China. Environmental awareness has grown significantly among citizens, stimulated by the widespread smog pollutions and recent massive environmental disasters among other factors. The enormous and strong reaction to journalist Chai Jing's 2015 documentary Under the Dome, which gathered over $\mathbf{3 0 0}$ million views in merely two days, is a testimony to the transition and indicates a great bottom-up force that demands the attention of the administration. In recent years, the evaluations of administrative achievements of local officials have also shifted gradually from a dominant emphasis on economy, represented by the growth rate of Gross Domestic Products, to include a more balanced agendas of managing the development of a city, reflected in such new slogans like LOHAS, appropriately translated into Chinese as "happy life," which often appear in planning documents. The compression of the real estate bubble, to a certain degree, mitigates the fever of new towns and large-scale developments. Medianor small-scale infill developments are encouraged, which should bring opportunities to "fix" some problems left by China's rapid urban expansion.

With these observations, I am optimistic in the promise of a more effective application of the eco-city concept in China's city building. However, a few pitfalls in implementing this idea, as indicated by the cases of Dongtan, Tianjin, and other existing projects, deserve the attention of mindful 
mayors, planners, architects, and developers. Inspired by $\mathrm{Yu}$ Kongjian's "Dialogue with Mayors," I want to conclude by offering eco-city practitioners three recommendations.

First, this "green" (ecological) shouldn't be confused with that "green" (landscape). Some policy-makers or planners took it for granted that an eco-city must have large green areas and high green coverage rate, and therefore introduced a loose urban form with wide spacing between buildings. While open spaces that provide ecologically and socially meaningful territoriality are certainly a critical component of an eco-city, high green coverage focusing on certain technical standards actually reduces urban density and represents a barrier to a more ecologically healthy compact city. In fact, New York City, with its extremely high density, is widely regarded as one of the greenest cities in the Unites States, thanks to its efficient metro system, highly walkable scale of street and block, cyclist friendly design, continuingly expanded waterfront open spaces system, and innovative retrofit of industrial structures and areas. Residents have easy access to all sorts of public spaces despite their compact sizes, and enjoy great social diversity. As another example, by placing high-density developments around Victoria Harbor and along metro lines, Hong Kong has been able to preserve large areas of natural reserves for numerous parks and recreations. Currently many new cities in China build large-scale landscapes in the manner of "urban beautification" without much ecological consideration, as Yu pointed out more than ten years ago, which actually leads to unsustainable urban pattern and environment.

Second, technologies rock, but they need a good urban design to fuse them together to create a real eco-city. Photovoltaics and wind turbines generate more renewable energy; new building materials make architecture more energy efficient; and smart technologies use big data to facilitate more effective management of the city and individual buildings. However, if these technologies are used in a fragmental manner and not based on a holistic ecological design and planning strategy, the project will have limited environmental impact and lead to a "handicapped" eco-city at best. Pioneers of ecological urbanism like Bill Dunster argue that "what works really brilliantly" for an eco-city tend to be the "simplest design decisions," namely, the traditional wisdom of passive design and planning, instead of the high technologies. Chinese eco-city builders are often attracted by technological tactics and focus on their usage, but ignore fundamental issues related to sustainable urban form. Their development guidelines, exemplified by Tianjin Eco-city's KPI system, are dominated by technical indexes. The result is the contradiction between the technological spectacle and the reactionary urban environment characterized by high-carbon patterns of super-block, segregated communities, and private automobile-based circulation. To solve such dilemma, a set of key indexes of urban design should be established and implemented along with the common environmental techniques and indexes to address such criteria, such as urban compactness (instead of FAR), walkability, open space, compatibility of programs, accessibility, integration of circulation, climate optimization, and legibility of urban form.

Finally, although top-down policies and measures are necessary to guarantee the planning and implementation of successful urban developments, eco-cities are essentially community-based projects and would not be complete without residents' participation. On one hand, governmental initiative, support, and management are crucial to get the such large-scale projects up and running, to lay out policies, plans, and guidelines, build critical infrastructure, attract investments, bring in international know-how, allocate funds, and coordinate different stakeholders in its long-term operation. On the other hand, the direct involvement of residents, private enterprises, and non-profit organizations would be more effective, at smaller scales yet not in smaller ways, to carry the projects further in executing the various agendas of the eco-city including inventing and adopting low-energy and low-carbon technologies, building and taking care of low-impact built environment, recycling reusable materials, promoting healthy life style, and enhancing public awareness of sustainability. To do so, some policy changes need to incorporate a bottom-up force; for example, allow small-scale power generators to be included into the national grid, channel incentives to individual users and not only monopolistic developers, and nurture a recycling lifestyle and recycling economy. In the context of China's urbanization, the governments that hold exclusive land ownership, the developers designated for production of space, and residents as occupants of the city constitute three anchors in the development of the eco-city. Many issues of previous eco-city attempts derived from the skew of this triangle, thus leaning toward either utopian projects dictated by the governments or utilitarian projects dominated by the interest of developers. It is only with community involvement and support that the ecocity movement can be rejuvenated and gear toward a truly sustainable path.

\section{ENDNOTES}

1 Richard Register, Ecocity Berkeley: Building Cities for a Healthy Future (Berkeley: North Atlantic Books, 1987).

2 United Nations Division for Sustainable Development, “Agenda 21," United Nations Conference on Environment \& Development Rio de Janerio, Brazil, 3 to 14 June 1992.

3 Simon Joss, et al, Eco-Cities: A Global Survey 2011 (London: University of Westminister, 2011); China Urban Science Research Council, Report of the Development of Low-Carbon Eco-city in China (Beijing: China Architecture \& Building Press, 2011).

4 http://greenleapforward.com. Accessed Nov. 16, 2013.

5 CO2 emissions in China rose from 2.7 metric tons per capita in 2001 to 6.7 metric tons per capita in 2011. http://data.worldbank.org/country/china, accessed Oct. 3, 2015. In 2008, China surpassed the US to become the world's largest carbon polluter. http://www3.epa.gov/climatechange/ghgemissions/ global.html, accessed Oct. 3, 2015.

6 National Development and Reform Commission (NDRC), "Medium and LongTerm Development Plan for Renewable Energy in China." September 2007. 